\title{
A questionnaire for screening the micronutrient intake of economically active South African adults
}

\author{
Marjanne Senekal ${ }^{1, *}$, Nelia P Steyn ${ }^{2}$ and Johanna $\mathrm{Nel}^{3}$ \\ 'Division of Human Nutrition, Department of Human Biology, Faculty of Health Sciences, University of Cape \\ Town, Anzio Road, 8001 Cape Town, South Africa: ${ }^{2}$ Chronic Diseases of Lifestyle Unit, Medical Research \\ Council, Cape Town, South Africa: ${ }^{3}$ Department of Logistics, University of Stellenbosch, Stellenbosch, \\ South Africa
}

Submitted 28 May 2008: Accepted 7 January 2009: First published online 27 March 2009

\begin{abstract}
Objective: The aim of the present study was to develop (phase 1) and validate (phase 2) a screening questionnaire to assess the adequacy of micronutrient intake of economically active South African adults.

Design: For identification of indicator foods to be included in the screening questionnaire (phase 1), a comprehensive, eighty-six-item, quantified FFQ that reflected the food sources of thirteen selected micronutrients associated with the nutrition-related health status of South Africans was developed and completed by 554 adults of all four major ethnic groups. Resulting dietary data were subjected to stepwise regression analyses to identify indicator foods to be included in the final screening questionnaire. For validation of frequency of intake reporting of specific food items included in the screening questionnaire (phase 2), a sample of sixty-six African and eighty-four white adult volunteers of both genders completed a $7 \mathrm{~d}$ record as well as the screening questionnaire. The frequency of intake of specific food items derived from the two methods was then compared using Spearman correlation coefficients.

Results: Phase 1 identified thirty indicator foods that formed the basis of the screening questionnaire. In phase 2 , significant correlations were found for the total group for twenty-two out of the thirty items in the questionnaire, with correlations being the best for white females and the poorest for African males and females.

Conclusions: A screening questionnaire (thirty-item FFQ) that can be used by researchers and health professionals to assess an individual's risk of inadequate micronutrient intake was developed and validated.
\end{abstract}

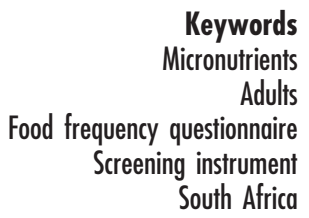

Keywords

Adults

South Africa
Primary prevention (health promotion), as opposed to secondary prevention (risk reduction) and tertiary prevention (treatment and rehabilitation), aims to ensure the health and well-being of groups of people ${ }^{(1)}$. One of the most important aspects to be addressed in primary intervention initiatives is adequate food intake (quantity and quality) to ensure optimal intake of energy, macro- and micronutrients. Adequate intake of micronutrients, including vitamins and minerals, is important not only to prevent the development of deficiency diseases such as vitamin A deficiency and Fedeficiency anaemia, but also contributes to the prevention of chronic diseases of lifestyle ${ }^{(1)}$.

One method that can be utilized to facilitate the early detection of nutritional imbalances is the use of screening procedures, including dietary evaluations ${ }^{(2,3)}$. Screening instruments can be completed by the subject/client or administered by an interviewer/health professional ${ }^{(4)}$. The purpose of a dietary screening tool is usually not to produce accurate estimates of nutrient intake by individuals or groups, nor to rank or categorise people accurately on that variable. The purpose is rather to identify individuals or groups at risk of low intakes. On the basis of this type of assessment, groups can be monitored to study the association between their health and indicators of dietary intake; or individuals can be counselled or subjected to an intervention programme; or individuals can be subjected to second-stage screening for more precise assessment of dietary intake and nutritional risk before action is taken ${ }^{(2,4)}$. Self-administered screening instruments can also be regarded as valuable educational tools in that awareness can be created regarding the adequacy and healthfulness of an individual's dietary intake ${ }^{(3)}$. The present paper describes the development (phase 1) and validation (phase 2) of a self- or health worker-administered questionnaire for screening the micronutrient intake of South African adults. As self-administration of the questionnaire 
would require a reasonable level of literacy (reading and writing), the target group for this research was specified to be economically active South Africans, who were assumed to have the required literacy and comprehension level.

\section{Phase 1: development of the screening questionnaire}

\section{Metbods of phase 1}

Following consultation with a panel of three dietary methodology experts, it was decided that the screening questionnaire to be developed should comply with the following criteria: (i) it had to be short and easy to complete without supervision; (ii) it had to reflect usual dietary intake; (iii) it had to be ethnically/culturally sensitive (recognition and accommodation of different South African population groups); and (iv) it had to facilitate the identification of potential problems with micronutrient intake. The expert panel recommended that a short, semi-quantified, FFQ format had the potential to meet these stated criteria.

An FFQ includes a list of food items known to be the major sources of the dietary components (micronutrients) in question ${ }^{(4,5)}$. The validity of any FFQ depends largely on the completeness/adequacy of this food list ${ }^{(6,7)}$. The expert panel recommended that in order to develop a list of indicator foods to be included in the screening questionnaire, a comprehensive quantified FFQ that included important sources of micronutrients related to common nutrition-related health problems experienced by South Africans should first be developed and tested. The resulting data could then be subjected to stepwise regression analyses to identify the necessary indicator foods.

\section{Compilation of the comprehensive quantified FFQ}

To identify micronutrients that needed to be included in the comprehensive list of food items, the main nutrition-related chronic diseases of lifestyle relevant to South Africans were first identified from a South African Medical Research Council report of the Chronic Diseases of Lifestyle Unit ${ }^{(8)}$. These diseases include hypertension, dyslipidaemia, diabetes mellitus and impaired glucose tolerance, lifestyleinduced cancers, stroke and osteoporosis. Micronutrients that are typically associated with the development/prevention of these diseases include the following thirteen nutrients: $\mathrm{Ca}, \mathrm{Mg}, \mathrm{Zn}, \mathrm{Fe}$, vitamin A, vitamin $\mathrm{E}$, thiamin, riboflavin, niacin, vitamin $\mathrm{B}_{6}$, vitamin $\mathrm{B}_{12}$, folate and vitamin $\mathrm{C}^{(1,8,9)}$. Second, micronutrient deficiencies that are endemic in South African populations, namely Fe and vitamin A deficiencies, were identified from a meta-analysis of dietary surveys $^{(9)}$ as well as national nutritional status surveys ${ }^{(10,11)}$.

Subsequently, the main sources of the thirteen nutrients were identified from the South African food composition tables ${ }^{(12)}$ and nutrition textbooks ${ }^{(1,13)}$. The criteria formulated by Willett ${ }^{(7)}$ were used to guide this process: (i) the food must have a substantial content of the nutrient(s) of interest; (ii) the food should be eaten reasonably often by an appreciable number of the target group; and (iii) the use of the food must vary from person to person. To ensure cultural/ethnic sensitivity ${ }^{(14)}$, the foods most commonly consumed by the different ethnic groups in South Africa were identified from reports by the National Programme for Nutrition Intervention of the South African Medical Research Council ${ }^{(15-17)}$. All of this information was combined to compile a list of eighty-six food items that are commonly consumed by adult South Africans and can be regarded as important sources of the identified micronutrients. Items such as sugar, candy, jams, syrup and energy drinks that are not micronutrientdense were not included in the food list. For frequency of intake reporting, the following response categories were selected based on the evaluation of a number of $\mathrm{FFQ}^{(18-23)}$ : seldom/never, 1-3 times/month, 1-3 times/ week, 4-6 times/week, 1 time/d, 2 times/d and 3 or more times/d. For portion size estimation an average serving size was specified in the questionnaire. These serving sizes were calculated using exchange lists adapted for mean portion sizes reported in South African dietary surveys $^{(15-17,24)}$. In this regard it is important to note that most of the variation in the intake of a food item in an FFQ is explained by frequency of intake and not necessarily by estimated portion size ${ }^{(7)}$. Accurate frequency estimation should therefore be a key focus in ensuring the validity of dietary data generated using an FFQ.

The resulting draft questionnaire was completed by twenty African and sixteen white South Africans of both genders as a pilot test, after which a few minor changes were made.

Sample for completion of the comprehensive FFQ and subsequent generation of the screening questionnaire The sample for phase 1 of the study was randomly drawn from the South African National Database, which is the largest consumer database in South Africa and comprised a sampling frame of more than 7 million economically active adults, i.e. consumers between the ages of 18 and 65 years, at the time of the study. The sampling frame included names and addresses of $52 \%$ white, $30 \%$ mixed ancestry, $11 \%$ Asian and 6\% African South Africans. A random sample of 2100 was drawn to be proportionally representative of all ethnic groups in the database, and to include at least one small town and one city from each of the nine provinces in the final sample. Since mailed questionnaires are known to have a poor response, a very large sample was mailed to ensure a response of at least $25 \%(n \approx 500)$.

\section{Ethical issues}

The research proposal was approved by the Ethics Committee of the University of Limpopo, South Africa. Detailed information concerning the aim of the research was included in an introductory letter that accompanied the eighty-six-item quantified FFQ. Confidentiality and 
anonymity were ensured. The completion and return of the questionnaire served as indication of voluntary participation and informed consent.

\section{Data collection and processing}

The FFQ was mailed to respondents together with a prepaid return envelope. General instructions regarding completion of the questionnaire as well as specific guidelines for portion size estimation were included on the cover page of the questionnaire. After the due date for return of questionnaires had passed, a reminder was mailed to the non-responders. A second reminder followed the first one. The main researcher scrutinised each questionnaire for completeness and quality. Twenty-six out of the 580 returned questionnaires were not included in the analyses. A questionnaire was excluded from analysis if the following was found: (i) whole page(s) not completed; (ii) the same frequency of intake indicated for a number of consecutive items on the list; and (iii) unrealistically high frequencies indicated. For quantification purposes the specified serving size was multiplied with the frequency of intake. In cases where the frequency was specified as a range e.g. 1-3 times/month, the frequency was taken as the midpoint of the range.

Statistical analysis for generation of the screening questionnaire from the dietary intake database

Statistical analyses were conducted using the SAS statistical software package version $6 \cdot 11$ (SAS Institute Inc., Cary, NC, USA). To identify food items that were the most important sources of each nutrient in question, stepwise regression analyses were performed as described by Willett $^{(7)}$. According to this procedure, the food item that explains the most between-person variance in the intake of a specific nutrient is identified as the first independent variable, the food item that explains the most variance not accounted for by the first food is the second independent variable, and so on. The contribution made by a specific food item is reflected in the change in the cumulative $R^{2}$. When the cumulative $R^{2}$ for a specific nutrient in the analyses reached $0 \cdot 7$, which is indicative of a correlation coefficient of $0 \cdot 84$, the food items in the regression model were taken as the best sources of a particular nutrient. This method identifies the food items that discriminate most between individuals rather than those that contribute to absolute intake. It should be kept in mind that the $R^{2}$ value will accumulate more rapidly for those nutrients that are highly concentrated in a few foods, e.g. vitamin $\mathrm{C}$, than for those that are dispersed throughout many foods, e.g. thiamin. According to Willett ${ }^{(7)}$ a limitation of this method is that if several hundred food variables are included in an original list of potential foods, some will enter as 'statistically significant' predictors on the basis of chance alone. The shorter the list of foods and the larger the sample size, the smaller is the chance of including unimportant contributors of a nutrient. The regression analyses were completed for the total group as well as for each ethnic group separately. Prominent differences in the rankings of food items between the four ethnic groups were taken into consideration in the final selection of food items to be included in the screening questionnaire.

\section{Results and discussion of phase 1}

A sociodemographic profile of the participants in phase 1 of the development procedure is presented in Table 1. The proportions from the various ethnic groups who participated were: Africans $27 \%$, Indians 12\%, mixed

Table 1 Sociodemographic profile (column \%) of the study population involved in phase 1 of the study: development of the screening questionnaire ( $n$ 554)

\begin{tabular}{|c|c|c|c|c|c|}
\hline Variable & Africans ( $n$ 149) & Mixed ancestry ( $n$ 102) & Asians ( $n$ 63) & Whites (n 240) & Total group ( $n$ 554) \\
\hline \multicolumn{6}{|l|}{ Gender } \\
\hline Female & $48 \cdot 7$ & $60 \cdot 8$ & $49 \cdot 2$ & $53 \cdot 3$ & $53 \cdot 0$ \\
\hline Male & $51 \cdot 3$ & $39 \cdot 2$ & $50 \cdot 8$ & $46 \cdot 7$ & $47 \cdot 0$ \\
\hline \multicolumn{6}{|l|}{ Age (years)* } \\
\hline$<25$ & $8 \cdot 8$ & $15 \cdot 8$ & $14 \cdot 3$ & $7 \cdot 5$ & $10 \cdot 1$ \\
\hline $25-34$ & $27 \cdot 0$ & $37 \cdot 6$ & $22 \cdot 2$ & $24 \cdot 6$ & $27 \cdot 5$ \\
\hline $35-44$ & $37 \cdot 2$ & $17 \cdot 8$ & $34 \cdot 9$ & $19 \cdot 2$ & $25 \cdot 5$ \\
\hline $45-54$ & $15 \cdot 5$ & $11 \cdot 9$ & $23 \cdot 8$ & $27 \cdot 9$ & $21 \cdot 2$ \\
\hline $55-65$ & $11 \cdot 5$ & $16 \cdot 8$ & $4 \cdot 8$ & $20 \cdot 8$ & $15 \cdot 7$ \\
\hline \multicolumn{6}{|l|}{ Highest level of educationt } \\
\hline Primary (grades 1-7) & $12 \cdot 2$ & $21 \cdot 8$ & $3 \cdot 2$ & 0 & $7 \cdot 6$ \\
\hline Secondary (grades 8-10) & $15 \cdot 0$ & $39 \cdot 6$ & $27 \cdot 0$ & $12 \cdot 6$ & $20 \cdot 1$ \\
\hline Secondary (grades $11+12$ ) & $29 \cdot 3$ & $25 \cdot 7$ & $36 \cdot 5$ & $32 \cdot 6$ & $30 \cdot 8$ \\
\hline Tertiary & $43 \cdot 5$ & $12 \cdot 9$ & $33 \cdot 3$ & $54 \cdot 8$ & $41 \cdot 5$ \\
\hline \multicolumn{6}{|l|}{ Employmentł } \\
\hline Student/housewife & $7 \cdot 4$ & $26 \cdot 7$ & $33 \cdot 3$ & $21 \cdot 3$ & $20 \cdot 2$ \\
\hline Full-time employed & $81 \cdot 1$ & $44 \cdot 6$ & $57 \cdot 1$ & $68 \cdot 8$ & $66 \cdot 1$ \\
\hline Unemployed & $4 \cdot 7$ & $20 \cdot 8$ & $9 \cdot 5$ & $2 \cdot 1$ & $7 \cdot 2$ \\
\hline Retired & $6 \cdot 8$ & $7 \cdot 9$ & 0 & $7 \cdot 5$ & $6 \cdot 5$ \\
\hline
\end{tabular}

$\begin{aligned}{ }^{*} \chi^{2} & =49 \cdot 7(\mathrm{df}=12), P<0 \cdot 0001 \\ +\chi^{2} & =125 \cdot 0(\mathrm{df}=9), P<0 \cdot 0001\end{aligned}$

$\ddagger \chi^{2}=67 \cdot 6(\mathrm{df}=9), P<0 \cdot 0001$. 
Table 2 Indicator food items* identified through stepwise regression analyses for each of the specified micronutrients $(n$ 528)

\begin{tabular}{|c|c|c|c|}
\hline Nutrient & $R^{2}$ & $\begin{array}{l}\text { No. of food } \\
\text { items }\end{array}$ & Food items \\
\hline $\mathrm{Ca}$ & 0.831 & 5 & Cheddar cheese, whole milk, low-fat milk, green beans, citrus (fruits and juice) $\dagger$ \\
\hline $\mathrm{Mg}$ & $0 \cdot 763$ & 10 & $\begin{array}{l}\text { Brown bread, whole wheat bread, legumes, peanuts, avocado pear, orange juice, spinach, onion } \\
\text { (raw or cooked), mixed vegetables (carrots, corn, peas, beans), salty condiments }\end{array}$ \\
\hline $\mathrm{Fe}$ & $0 \cdot 798$ & 10 & $\begin{array}{l}\text { Red meat (low-fat), fried chicken, organ meat, eggs, brown bread, breakfast cereals (fortified), } \\
\text { legumes, orange juice, spinach, green peas }\end{array}$ \\
\hline $\mathrm{Zn}$ & $0 \cdot 795$ & 9 & $\begin{array}{l}\text { Red meat low- and medium-to-high fat, fried chicken, organ meat, brown bread, cheddar } \\
\text { cheese, peanuts, green beans, chicken without skin }\end{array}$ \\
\hline Vitamin A & 0.943 & 7 & $\begin{array}{l}\text { Mangoes, carrots, sweet potatoes, pumpkin, tomato/onion mix, mixed vegetables (as above), } \\
\text { spinach }\end{array}$ \\
\hline Vitamin E & 0.895 & 8 & $\begin{array}{l}\text { Fried onions, soft margarine, nuts, fried potatoes, sweet potatoes, avocado pears, fried fish, } \\
\text { fat cakes }\end{array}$ \\
\hline Vitamin C & 0.931 & 5 & Citrus fruits, guavas, orange juice, other fruit juice, tomatoes (raw or cooked) \\
\hline Thiamin & $0 \cdot 771$ & 8 & $\begin{array}{l}\text { Pickled meat, fish, chicken, breakfast cereal (fortified), oat porridge, maize porridge, potatoes, } \\
\text { health bars, bananas, green peas, potato crisps }\end{array}$ \\
\hline Riboflavin & $0 \cdot 830$ & 7 & $\begin{array}{l}\text { Health bars, organ meat, breakfast cereal (fortified), whole milk, low-fat milk, mixed vegetables } \\
\text { (as above), mangoes }\end{array}$ \\
\hline Niacin & $0 \cdot 805$ & 6 & $\begin{array}{l}\text { Red meat (medium-to-high fat), chicken (with and without skin), breakfast cereal (fortified), } \\
\text { health bars, peanut butter, peanuts, bananas, green beans }\end{array}$ \\
\hline Vitamin $B_{6}$ & $0 \cdot 745$ & 5 & Breakfast cereal (fortified), potatoes, bananas, orange juice, potato crisps \\
\hline Vitamin $\mathrm{B}_{12}$ & 0.991 & 4 & Organ meat, tinned fish, red meat (low-fat), meat pies \\
\hline Folate & $0 \cdot 801$ & 7 & Breakfast cereal (fortified), legumes, citrus fruits, avocado pear, spinach, tomatoes, green peas \\
\hline
\end{tabular}

${ }^{*}$ Food items indicated in italics were included in the final version of the screening questionnaire.

tFortification of fruit juice with $\mathrm{Ca}$ could be responsible for high Ca values in citrus.

ancestry $18 \%$ and whites $43 \%$. It must be borne in mind that the ethnic profile of economically active South Africans represented in the South African National Database does not reflect the country's general demographic profile, which was $78 \%$ African of whom $31 \%$ were unemployed and $54 \%$ were literate at the time of the study ${ }^{(25,26)}$. It can therefore be said that the sample was more representative of the educated employed South African, irrespective of ethnic group, and the application of the screening questionnaire should be aimed at this particular group. Although the response rate was only $28 \%$, the sample size was large enough to enable us to conduct meaningful statistical analyses to derive the screening questionnaire.

The most important food sources of each of the selected thirteen micronutrients identified by the regression analyses are presented in Table 2. A food item was finally selected for the screening questionnaire by the expert panel if it was the primary source of one or two nutrients, or a secondary source of a number of nutrients. Descriptions of preparation methods and fat content of food items were not included in the final version of the screening questionnaire (Table 3). It was also decided to limit the recall period of the screening questionnaire to one week to reduce the memory burden on the respondent and to simplify the frequency concept. Except for the 1-3 times/month category, all the response categories included in the eighty-six-item FFQ were retained. In the final version of the screening questionnaire the respondent is not expected to indicate portion size.

For quantitative micronutrient risk assessment purposes, the daily intake of each of the thirteen micronutrients reflected by the thirty food items in the screening questionnaire can be computed by using either a standard dietary assessment program or a tailored calculation program. The actual calculation should be based on the frequency of intake indicated by the respondent using standard portion sizes. Micronutrient intake can then be compared to the relevant dietary reference intake (Recommended Dietary Allowance (RDA) or Adequate Intake (AI)) for individual risk assessment ${ }^{(27)}$. Suggested cut-off points are: serious risk, $<67 \%$ of $\mathrm{RDA}$ or $\mathrm{AI}$; mild risk, $\geq 67 \%$ and $<100 \%$ of RDA or $\mathrm{AI}$; no risk, $\geq 100 \% \mathrm{RDA}$ or $\mathrm{AI}^{(28)}$.

\section{Phase 2: assessment of the validity of frequency reporting in the screening questionnaire}

\section{Methods of phase 2}

The underlying question addressed by this phase of the study was whether the screening questionnaire provided a true reflection of the usual intake of the selected micronutrients by an individual. Construct, face and content validity of the instrument, i.e. whether it actually had the potential to reflect the usual intake of the micronutrients in question, were ensured by the process that was followed in the development of the questionnaire in phase 1 . However, whether the concept of 'frequency of intake' was well understood, and whether the frequency indicated in the questionnaire was a true reflection of actual frequency of intake, needed to be assessed.

\section{Sample}

For these purposes a sample of sixty-six African and eightyfour white adult volunteers of both genders, with a sociodemographic profile comparable to that of respondents who participated in phase 1 of the study, was recruited. 


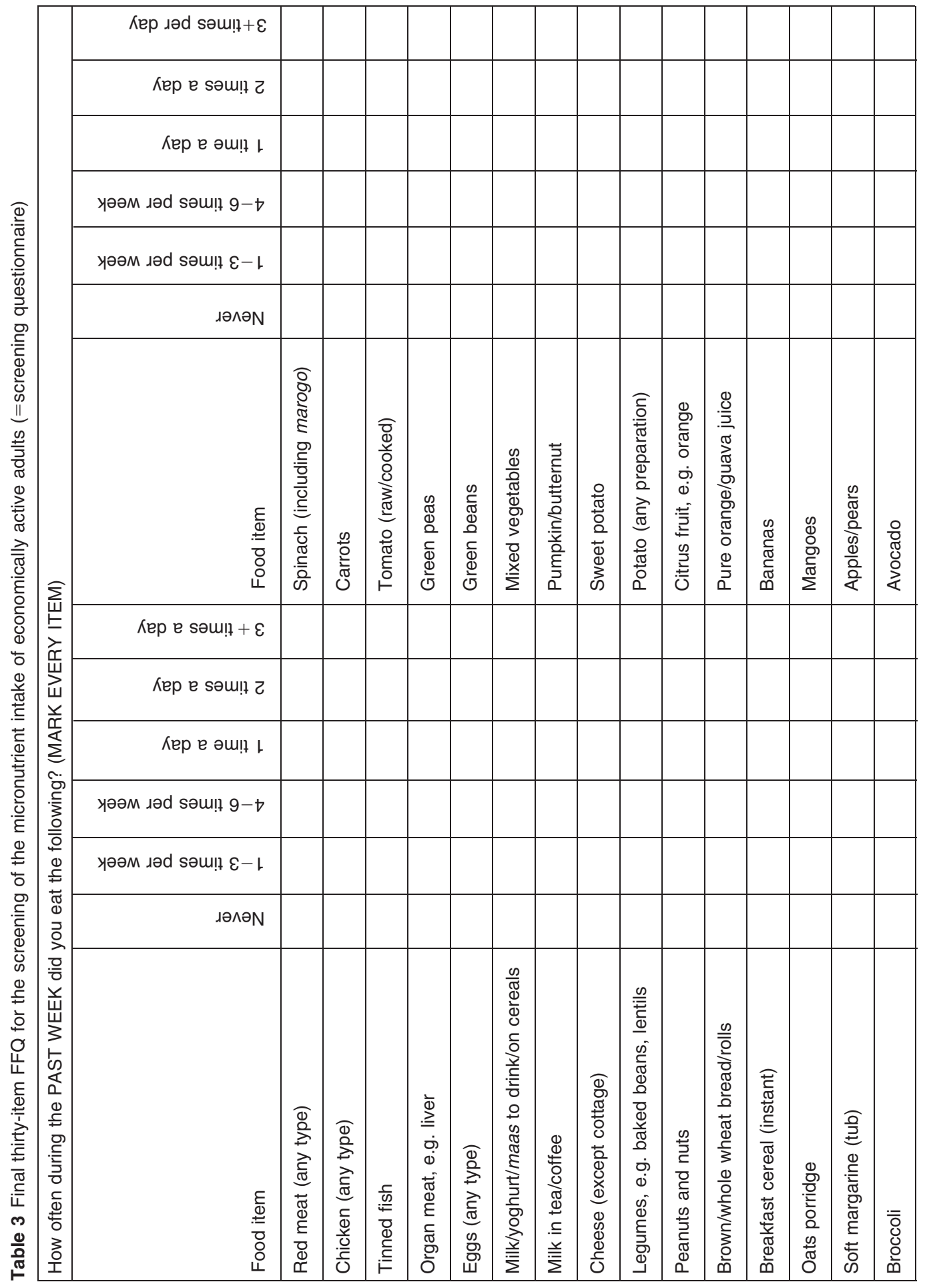


Recruitment drives focused on employees of two South African universities. Potential participants for the validation study were invited to attend a session during which the aim and procedures of the study were explained, after which they could volunteer for participation.

\section{Validation method}

According to Brants et al. ${ }^{(29)}$, the dietary record method is the best comparison/calibration dietary method for an FFQ because the sources of error associated with both methods are largely independent. Therefore participants in this validation study were requested to keep a $7 \mathrm{~d}$ estimated food record to determine usual frequency of intake of the food items included in the screening questionnaire. Each participant received a booklet that included the necessary recording guidelines, which were explained to them by a registered dietitian trained for this purpose. The respondents completed the screening questionnaire two weeks after completion of the $7 \mathrm{~d}$ record during a personal session with the dietitian.

\section{Ethical issues}

The protocol for phase 2 of the study was also approved by the Ethics Committee of the University of Limpopo. Each participant signed a consent form.

\section{Data processing and analysis}

Statistical analyses were conducted using the SAS statistical software package version $6 \cdot 11$ (SAS Institute Inc.). The $7 \mathrm{~d}$ records were analysed to generate an indication of frequency of intake of specific food items. For example, the number of times red meat was eaten during the recording week was counted, irrespective of the preparation method, to generate an indication of the frequency of red meat intake. Spearman correlation coefficients were computed to determine the relationship between the frequency of intake indicated in the screening questionnaire for a particular food item and the frequency of intake derived from the $7 \mathrm{~d}$ records.

\section{Results and discussion of phase 2}

The sociodemographic profile of the study population of phase 2 of the study, presented in Table 4 , indicates that the majority of participants were employed and educated at secondary and tertiary levels. The correlations between frequency of intake of specific food items recorded on the screening questionnaire and that derived from the $7 \mathrm{~d}$ record are presented in Table 5. Significant Spearman correlation coefficients were found for twenty-two of the thirty items ( $r$ ranging from $0 \cdot 24$ to $0 \cdot 62$ ) in the total group ( $n$ 150), for nineteen of the thirty items ( $r$ ranging from $0 \cdot 27$ to $0 \cdot 66$ ) among females $(n 81)$ and for fifteen of the thirty items ( $r$ ranging from 0.25 to $0 \cdot 77$ ) among males ( $n$ 69). When considering the gender groups within the two ethnic groups, it becomes evident that the best correlations were found for white females and the poorest for both African males and females. Generally the strongest correlations were found for food items such as red meat, milk, cheese, bread, breakfast cereal, margarine, some vegetables, citrus fruit, bananas and pears/apples. The weakest correlations were found for most vegetables, tinned fish, chicken, legumes and orange/guava juice. When interpreting these results it should be borne in mind that the screening questionnaire requests the respondent to report on frequency of intake of specific food items over the "past week'. As the $7 \mathrm{~d}$ food record was completed two weeks before the screening questionnaire was completed, food items that are consumed only two times or less per month could have been recorded using one method but not the

Table 4 Sociodemographic profile (column \%) of the study population involved in phase 2 of the study: validation of the frequency reporting in the screening questionnaire $(n 150)$

\begin{tabular}{|c|c|c|c|}
\hline Variable & Africans $(n 66)$ & Whites ( $n$ 84) & Total group ( $n$ 150) \\
\hline \multicolumn{4}{|l|}{ Gender } \\
\hline Male & $45 \cdot 5$ & $47 \cdot 1$ & $46 \cdot 4$ \\
\hline Female & $54 \cdot 5$ & $52 \cdot 9$ & $53 \cdot 6$ \\
\hline \multicolumn{4}{|l|}{ Age (years)* } \\
\hline$<25$ & $12 \cdot 2$ & $18 \cdot 8$ & $15 \cdot 9$ \\
\hline $25-34$ & $51 \cdot 5$ & $21 \cdot 2$ & $34 \cdot 4$ \\
\hline $35-44$ & $22 \cdot 7$ & $24 \cdot 7$ & $23 \cdot 8$ \\
\hline $45-54$ & $13 \cdot 6$ & $24 \cdot 7$ & $19 \cdot 9$ \\
\hline $55-65$ & 0 & $10 \cdot 6$ & $5 \cdot 0$ \\
\hline \multicolumn{4}{|l|}{ Highest level of educationt } \\
\hline Primary (grades 1-7) & $3 \cdot 0$ & 0 & $1 \cdot 3$ \\
\hline Secondary (grades 8-10) & $7 \cdot 6$ & $1 \cdot 2$ & $4 \cdot 0$ \\
\hline Secondary (grades $11+12$ ) & $21 \cdot 2$ & $10 \cdot 6$ & $15 \cdot 2$ \\
\hline Tertiary & $68 \cdot 2$ & $88 \cdot 2$ & $79 \cdot 5$ \\
\hline \multicolumn{4}{|l|}{ Employment‡ } \\
\hline Student/housewife/part time employed & $22 \cdot 7$ & $28 \cdot 2$ & $25 \cdot 8$ \\
\hline Full-time employed & $69 \cdot 7$ & $64 \cdot 7$ & $66 \cdot 9$ \\
\hline Unemployed & $7 \cdot 6$ & 0 & $3 \cdot 3$ \\
\hline Retired & 0 & $7 \cdot 1$ & $4 \cdot 0$ \\
\hline
\end{tabular}

${ }^{*} \chi^{2}=20.3(\mathrm{df}=5), P=0.001$.

$+\chi^{2}=11.0(\mathrm{df}=3), P=0.01$.

$\neq \chi^{2}=11 \cdot 8(\mathrm{df}=5), P=0.04$. 


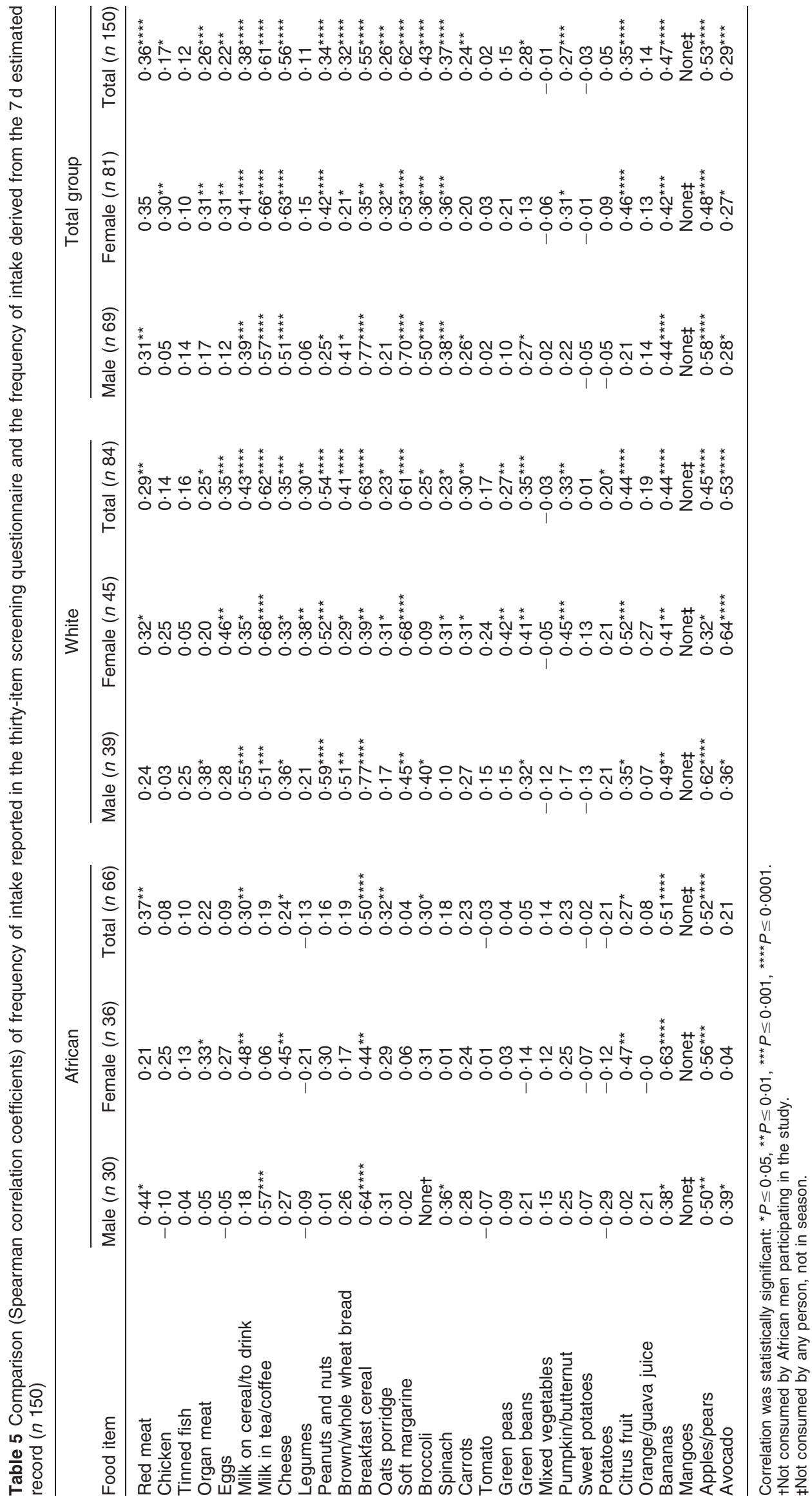


other, which could explain low correlation coefficients for some items. Many of the food items for which no significant correlations were found are in fact items that are consumed less frequently by South Africans ${ }^{(28)}$. These include the following: tinned fish, peas, mixed vegetables, peanuts and nuts, sweet potatoes, fruit juices, eggs, legumes and tomatoes.

\section{Conclusions and recommendations for application: phases 1 and 2}

A comprehensive procedure was followed to develop a questionnaire to screen the micronutrient intake of economically active South Africans. The result is a brief thirty-item FFQ (screening questionnaire) on which respondents indicate frequency of intake of each food item. Micronutrient intakes can then be computed using the indicated frequency of intake and standard portion sizes. Intakes should be compared with reference standards (i.e. dietary reference intakes) to provide an indication of deficiency risk for each specified micronutrient. The screening questionnaire can be used by researchers and health professionals to assess the micronutrient intake risk of individuals in a simplified and quick manner. The possibility of publishing the screening questionnaire, as well as appropriate guidelines to improve micronutrient intake where necessary in the lay media or on the Internet, can be considered.

Finally, as the screening questionnaire was developed for use in economically active South Africans, its application in screening the micronutrient intake of other groups of South Africans individuals, including those in the lowest socio-economic groups who may be less economically active and even illiterate, is not recommended without further assessment of the screening questionnaire's validity in such groups of individuals.

\section{Acknowledgements}

The study was funded by the Vitamin Information Service, Roche Laboratories and the Universities of Limpopo and Stellenbosch. There is no conflict of interest. M.S. planned the study, helped with data analyses and was the main author. N.P.S. helped in planning, carried out the field work and assisted in writing up the study. J.N. undertook the data analyses and interpretation of the data.

\section{References}

1. Mahan LK \& Escott-Stump S (2008) Krause's Food Nutrition and Diet Therapy, 12th ed. Philadelphia, PA: Mosby Saunders Elsevier Inc.

2. Block G, Clifford C, Naughton MD, Henderson M \& McAdams M (1989) A brief dietary screen for high fat intake. J Nutr Educ 21, 199-207.

3. Sahyoun NR, Jaques PF, Dallal GE \& Russel RM (1997) Nutrition screening initiative checklist may be a better awareness/educational tool than a screening one. J Am Diet Assoc 97, 760-764.

4. Lee RD \& Nieman DC (2003) Nutritional Assessment, 3rd ed. London: McGraw-Hill.

5. Nelson M \& Bingham S (1997) Assessment of food consumption and nutrient intake. In Design Concepts in Nutritional Epidemiology, 2nd ed., pp. 123-169 [BM Margetts and M Nelson, editors]. Oxford: Oxford University Press.

6. Baghurst KI (1992) The food frequency technique and its relevance to population surveys in Australia. Aust J Nutr Diet 49, 101-105.

7. Willett W (1998) Nutritional Epidemiology, 2nd ed. Oxford: Oxford Press.

8. Fourie J \& Steyn K (1995) South African Research Council Technical Report: Chronic Diseases in South Africa. Parow: Medical Research Council.

9. Vorster HH, Jerling JC, Oosthuizen W, Becker P \& Wolmerans P (1995) Nutrient Intakes of South Africans: An Analysis of the Literature (SANNS Group Report). Isando: Roche.

10. South African Vitamin A Consultative Group (1996) Child malnutrition in South Africa. Nutriview 1, 1-3.

11. Labadarios D (editor) (2000) The National Food Consumption Survey (NFCHS): Children aged 1-9 years, South Africa. Pretoria: Department of Health.

12. Langenhoven M, Kruger M, Gouws E \& Faber M (1991) MRC Food Composition Tables, 3rd ed. Parow: Medical Research Council.

13. Smolin LA \& Grosvenor MB (2003) Nutrition: Science \& Applications, 4th ed. London: Saunders College Publications.

14. Teufel NI (1997) Development of culturally competent food-frequency questionnaires. Am J Clin Nutr 65, Suppl., 1173S-1178S.

15. Wolmerans P, Langenhoven ML, Benade AJS, Swanepoel ASP, Kotze TJ \& Rossouw JE (1988) Intake of macronutrients and their relationship with total cholesterol and high-density lipoprotein cholesterol. S Afr Med J 73, $140-148$.

16. Langenhoven ML, Steyn K \& van Eck M (1988) The food and meal pattern in the Cape Peninsula coloured population. Ecol Food Nutr 22, 107-116.

17. Bourne LT, Langenhoven ML, Steyn K, Jooste PL, Nesamvuni AE \& Laubscher JA (1994) The food and meal pattern in the urban African population of the Cape Peninsula, South Africa: The Brisk study. S Afr Med J 40, 140-148.

18. Eck LH, Klesges RC, Hanson CL, Slawson D, Portis L \& Lavasque ME (1991) Measuring short-term dietary intake: development and testing of a 1-week food frequency questionnaire. J Am Diet Assoc 50, 220-228.

19. Hammond J, Nelson M, Chinn S \& Rona RJ (1993) Validation of a food frequency questionnaire for assessing dietary intake in a study of coronary heart disease risk factors in children. Eur J Clin Nutr 47, 242-250.

20. Jacques PF, Sulsky SI, Sadowski JA, Phillips JC, Rush D \& Willet WC (1993) Comparison of micronutrient intake measured by a dietary questionnaire and biochemical indicators of micronutrient status. Am J Clin Nutr 57, 182-189.

21. Caan B, Coates A \& Schaffer D (1995) Variations in sensitivity, specificity, and predictive value of a dietary fat screener modified from Block et al. J Am Diet Assoc 95, 564-568.

22. Subar AF, Thompson FE \& Smith AF (1995) Improving food frequency questionnaires: a qualitative approach using cognitive interviewing. J Am Diet Assoc 95, 781-788.

23. Wilson P \& Howarth C (1996) Validation of a short frequency questionnaire for assessment of dietary calcium intake in women. Eur J Clin Nutr 50, 220-228. 
24. Vorster HH, Oosthuizen W, Jerling JC, Veldman FJ \& Burger HM (1997) The Nutritional Status of South Africans: A Review of the Literature (Part II). Durban: Health Systems Trust.

25. Lehohla P (2005) 'Race' is just one variable in monitoring change. Statistics South Africa. http://www.statssa. gov.za/news_archive/12may2005_1.asp (accessed May 2008).

26. Development Bank of Southern Africa (1994) Race Relations Survey 1993/1994. Johannesburg: SAIRR.
27. Institute of Medicine, Food and Nutrition Board (1998) Dietary Reference Intakes. Washington, DC: National Academy Press.

28. Nel JH \& Steyn NP (2002) Report on South African Food Consumption Studies Undertaken Amongst Different Population Groups (1983-2000). Pretoria: Department of Health.

29. Brants HAM, Löwik MRH, Brussaard JH, Kistemaker C \& Van Erp-Baart AMJ (1997) Food consumption methods. Development, reproducibility and validation of a food frequency questionnaire for vitamin $\mathrm{B}_{6}$. Eur J Clin Nutr 51, Suppl., S12-S18. 